\title{
RENDER E PRODUZIR NO ESPORTE: RENDIMENTO OBRIGATÓRIO OU RENDIMENTO NECESSÁRIO?
}

\author{
Andrize Ramires Costa * \\ Elenor Kunz **
}

\begin{abstract}
RESUMO
A expressão "esporte de rendimento" é demasiadamente conhecida entre profissionais da Educação Física e dos Esportes. Porém, o seu significado, em geral, remete apenas aos esportes de alto rendimento ou de competição. Aqui se pretende rediscutir a questão do rendimento no esporte, em especial para aqueles que não desejam ou não precisam de altos rendimentos, como é o caso do esporte escolar. Apresenta-se, assim, um plädoyer para um esporte de rendimento na escola onde o aluno é livre para render o que pode, e não obrigado a render o que não pode, ou seja, ir para além de suas capacidades.
\end{abstract}

Palavras-chave: Esporte. Ensino. Estudantes

\section{INTRODUÇÃO}

A temática do rendimento é seguidamente discutida para quase todas as atividades humanas. Vivemos numa sociedade de rendimento, e a escola, especialmente, é o lugar mais sagrado para preparar futuros profissionais para RENDER e prosperar.

Rendimento, portanto, é um conceito que quase todo mundo entende e considera evidente e inquestionável, ou seja, significa produzir cada vez mais, concorrer e competir. Mas será que é tão simples assim? Do ponto vista sociológico, segundo alguns autores como Trebels (2009), apoiado em Peter Heij (2006) e Van Strien (1972), apontam para duas diferenciações que precisam ser feitas quando se trata do rendimento no contexto social:

- Um rendimento sem vínculo - que se trata de um rendimento sob ameaças, até mesmo com agressões ao sujeito do rendimento. É o típico rendimento na perspectiva tecnológica do nosso mundo da informação e totalmente administrado;

- Um rendimento com vínculos que permite atividade(s) em conjunto, de forma coletiva, no qual todos os sujeitos envolvidos no rendimento se respeitam e se ajudam mutuamente.

Já para o Esporte, ainda segundo Trebels (2009) e com base em Gerd Hecker (1971) é possível fazer três distinções para o tema do rendimento:

1. O rendimento pode ser entendido fundamentalmente como uma atividade de movimento esportivo realizada com êxito;

2. Do mesmo modo, o rendimento pode ser entendido como uma atividade de movimento esportivo realizada com êxito, mas de forma coletiva; 
3. O terceiro conceito de rendimento no esporte é aquele que é facilmente encontrado no ranking esportivo, ou seja, na lista dos melhores resultados esportivos e suas classificações por tempo ou época e por eventos.

Esse entendimento, no entanto, fica perfeitamente compreensível para o esporte de competição ou, como também é conhecido, "de rendimento", porém fica a dúvida: o esporte que pessoas normais, em especial aquelas da escola, ou seja, na Educação Física Escolar praticam também pode ser explicado e entendido desta forma? Quais esclarecimentos teóricos podemos usar para fundamentar uma teoria do rendimento no esporte que não necessariamente se deriva do entendimento de Hecker acima para sua compreensão? Embora esse tema devesse ser abordado de forma mais abrangente e profunda, isto é impossível nesse espaço, por isso optamos em apresentar apenas uma pequena base sobre a qual novos e mais amplos aprofundamentos possam ser realizados.

\section{RENDER, PRODUZIR E GANHAR}

Estes são verbos muito utilizados numa sociedade de rendimento. As pessoas precisam render e produzir mais para ganhar mais, tanto no trabalho como nos estudos e também nos esportes. É simples, render e produzir se referem a superar obstáculos e resolver tarefas para ganhar ou para alcançar rendimentos cada vez maiores. Mais simples ainda é o fato de que o Rendimento é o resultado produzido ao se vencer obstáculos na realização de tarefas em suas diferentes dimensões sócio-culturais. Porém, assim tão simples 0 problema do render, produzir e ganhar, ou seja, do rendimento, não pode ser. Não pode haver rendimentos em si de forma absoluta, mas rendimentos vinculados a valores e sentidos. E para entendermos os valores e os sentidos presentes no ato do render e produzir, é preciso acrescentar fatos e dados sóciohistóricos do rendimento apresentado.

O rendimento é um dado objetivo, um produto alcançado por alguém individualmente ou de forma coletiva no sentido de uma comunidade ou de um País. Existem assim pelo menos dois fatores importantes que precisam ser analisados e conhecidos por quem assume as exigências sociais de produzir e render: as expectativas sociais e as expectativas individuais. Nota-se que, na maioria dos casos de exigências para o rendimento social como trabalho, estudos ou esportes, as expectativas individuais são subsumidas pelas expectativas sociais.

Mais complexo ainda é quando o rendimento alcançado de forma objetiva e mensurável não reflete ao render e produzir do ponto de vista individual ou coletivo justamente por não se poder medir e avaliar objetivamente as possibilidades subjetivas deste render e produzir. Exemplificando: deixamos o exemplo do esporte para mais adiante, mas aqui podemos trazer o caso das notas ou conceitos de alunos na escola. A diferença subjetiva de um rendimento ob- 
jetivamente alcançado não é possível ser avaliada. No caso, qual pode ser a diferença nas expectativas individuais de um aluno que obteve nota oito numa prova e de outro que tirou sete ou apenas seis? Do ponto de vista da relevância individual a partir das expectativas de rendimento, a nota seis pode significar um rendimento muito maior para um aluno do que a nota oito para outro aluno. Estamos falando do render, produzir para ganhar.

Se a questão é ganhar, podemos dizer que nos remete ao futuro, portanto, uma nota seis agora pode significar uma nota nove ou dez no futuro enquanto que a nota oito do outro aluno pode se repetir ou até ficar inferior. Enfim, quem ganhou mais: o aluno da nota seis ou o aluno da nota oito?

Ao render e produzir, podemos acrescentar certa liberdade individual ou coletiva em suas próprias expectativas, já o rendimento em geral atende a uma expectativa social dada. Exemplo: um excelente aluno na expectativa social é um aluno que tira sempre nota acima de nove, porém um aluno apenas bom com notas entre seis e sete poderá no final de seus estudos alcançar um rendimento socialmente mais satisfatório que o primeiro. Infelizmente, do ponto de vista pedagógico vale apenas o rendimento alcançado por etapa, disciplina, ano escolar, etc. $O$ render e o produzir no que tange ao crescimento individual ou coletivo na formação das condições de possibilidade de um rendimento com sentido não são levados em consideração.

Enfim, vivemos numa sociedade fortemente regida por princípios de rendimento que passam a valer como princípios regulativos para a organização da sociedade em classes e para que individualmente se possa hierarquizar nas devidas posições ou níveis sociais cada participante de uma sociedade dita democrática.

\section{O ESPORTE DE RENDIMENTO}

Embora o conceito de esporte de rendimento já seja do domínio público, pois é o esporte que todo mundo vê na Televisão e nas mídias em geral, ainda assim merece um destaque maior para o propósito desta análise.

Portanto, o esporte de rendimento de que estamos falando:

- Tem a competição e a concorrência como princípio fundamental para sua organização e funcionamento;

- Orienta-se na produção de rendimentos a partir do modelo olímpico do Mais Veloz, mais Alto e mais Forte (Citius, Altius, Fortius);

- Tem como regras básicas somente a Sobrepujança e as Comparações Objetivas e, em consequência, um processo incontornável de Selecionamento, Especialização e Instrumentalização;

- Seu Sentido e Significado maior será encontrado quando acontecer a total submissão dos praticantes às suas regras, gestos técnicos e exigências de resultados mensuráveis (uma função apenas comparativa do se-movimentar) 
- E, por último, o esporte de rendimento sempre exigirá locais e materiais padronizados para sua prática.

Como já salientamos acima, esse é o entendimento que a mídia em geral também divulga sobre o esporte, passando assim a, praticamente, ser o único modo de se entender e praticar esportes. Porém, se inclusive as crianças se deixam orientar nesse modelo de esporte, deve haver - como de fato há - muitos problemas com esse esporte. Por outro lado ainda, o esporte no modelo de alto rendimento há muito tempo pode ser classificado como um produto mercadológico, uma mercadoria de enorme valor comercial inclusive. O próprio atleta não é apenas o representante comercial dessa mercadoria, mas passa a ser ele próprio a mercadoria de alto valor em alguns casos. Isso também é um dos responsáveis para que mais e mais gente, entre as quais crianças por influência de pais e professores, interessam-se por esse esporte.

A enorme influência desse modelo de esporte sobre a maioria dos praticantes, sejam crianças, jovens ou adultos em diferentes instâncias, ou seja, treinando para alguma modalidade ou apenas praticando por prazer ou motivos de saúde, pode ser percebida por ocasião da proximidade de um grande evento esportivo como as Olimpíadas. Crianças em geral são mais sensíveis a estas influências quando procuram imitar o estilo do corte de cabelo ou da vestimenta de um de seus ídolos do esporte. Essa identificação com seus ídolos na maioria das vezes ultrapassa a simples imitação e conduta externa da criança ou do jovem, pois ele quer ser igual ao seu ídolo também quando brinca, joga ou pratica esportes. É nessa hora que muitas vezes surge a maior influência negativa desta identificação, ou seja, pela frustração de seu rendimento não ser nada parecido com a do seu ídolo.

Esse fenômeno da frustração pela identificação com a imagem de um ídolo ainda não foi suficientemente analisado do ponto de vista científico. Há necessidade de uma rigorosa verificação empírica deste problema. Porém, já é possível deduzir que esse fenômeno se estende para a vida social e cultural de crianças e jovens.

Não são poucas as vezes que se ouve de pais e professores que certos alunos (crianças e jovens) que facilmente se identificam com seus ídolos do esporte ou da música, em geral, não são nada produtivos no rendimento escolar. Por que será? O motivo não estaria principalmente no fato de que a identificação externa com um ídolo (justamente de grandes rendimentos) normalmente é acompanhada de uma grande frustração interna, a do sentimento de inferioridade em relação a seus ídolos e a total incapacidade de reação frente a essa frustração?

Assim, se não houver uma reação da escola frente a esse problema na oferta de possibilidades de rendimento onde todos possam alcançar ou realizar uma atividade de forma bem-sucedida, podemos esperar que nos anos vindouros o contingente de pessoas totalmente excluídas da sociedade de rendimen- 
to, bem como de pessoas com a grave doença da depressão venha a aumentar assustadoramente.

\section{RENDER NO ESPORTE SEM PRECISAR PROVAR RENDIMENTOS}

Já vimos que as exigências de rendimento nos esportes ocorrem muitas vezes mais pela imagem que praticantes têm do esporte de sua preferência pela televisão do que experimentando suas próprias capacidades com o esporte preferido.

Portanto, os alunos de uma aula de Educação Física também sofrem com este problema. E o com que um professor de Educação Física pode contribuir para que os alunos possam se desfazer destas imagens e buscar rendimentos a partir de suas próprias capacidades e limites? Como é possível introduzir a ideia para o aluno de uma necessidade de rendimento e não de uma obrigação de rendimento?

Os alunos precisam entender que para uma boa prática esportiva não é necessário cumprir com um rol de exigências, como as do treinamento, por exemplo, e nem é preciso saber praticar um esporte tão bem como os praticantes a que assistem em quadras de competição ou na televisão. Precisam saber, então, que também isso não traz nenhum tipo de prejuízo à imagem e aos valores pessoais do aluno.

Em síntese, o aluno deve descobrir que é possível render, até bastante, sem precisar a cada instante estar provando rendimentos nos padrões aceitáveis socialmente. Em outras palavras, pedagogicamente é muito mais relevante falar de um Rendimento Necessário em vez de um Rendimento Obrigatório.

Por isso, é importante analisar e entender, além do valor, o sentido do rendimento nos esportes. Qual a importância de um alto nível de exigência técnica para o rendimento no esporte? É evidente que um rendimento físico e técnico são necessários para uma boa prática esportiva, para uma prática que tenha sentido e prazer ao praticante. Porém, se nos orientarmos apenas nos padrões prefixados do rendimento destas dimensões, podemos exigir dos nossos alunos muitos rendimentos desnecessários e muitas vezes inclusive absolutamente falsos e negativos.

Volkamer (1987), um autor alemão dos esportes, consegue ilustrar um pouco melhor esses níveis de exigência para o rendimento no esporte através da compreensão mais apurada do sentido das regras esportivas, e assim será possível inclusive compreender melhor também o próprio esporte. São três os planos de regras no entendimento desse autor que precisam ser levados em consideração para entender esse sentido das regras e que levam a exigências de rendimento.

O "Primeiro Plano" para ele tem a ver com as Regras oficiais codificadas em artigos e parágrafos em que certas ações são reconhecidas ou condenadas para a modalidade em questão, como,por exemplo, os pontos no voleibol, o 
gol, uma bola fora, etc. Neste plano, então, pode-se aprender as regras decorando todos os artigos e parágrafos expressos em forma de livro de regras da modalidade. É através destas regras que podemos entender de que esporte se trata e como ele funciona. Regras neste plano, no entanto, não são suficientes para esclarecer melhor a totalidade do fenômeno esportivo.

Através destas regras, é difícil explicar para alguém não expert em futebol, no caso, o que é um impedimento ou por que isso ou aquilo é proibido. As informações em geral ficam sem sentido. Mas esse plano das regras codificadas deve, na verdade, para uma maior clareza sobre o esporte, ser precedido por outro plano, ou seja,O "Segundo Plano", o sentido de toda regra vale para garantir a Tensão necessária do esporte e assim, também, a dinamicidade, a igualdade de chances, a indeterminação dos resultados etc., ou seja, tudo aquilo que torna o esporte algo tão fascinante, tão empolgante. É por isso que o impedimento no futebol ou a condução no momento do toque ou manchete no voleibol são proibidos.

A codificação das regras precisa sempre levar em consideração estas relações tensas, de surpresas e de indeterminação de resultados, entre outras. Algo semelhante também podemos encontrar em outras instâncias da vida social, como no exemplo das regras de trânsito, embora seja possível verificar que o contrário precisa acontecer, ou seja, orientações seguras, previsibilidade e eficiência nos resultados concretos são a exigência. Porém, mais sentido se ganha ainda e mais compreensível se torna o esporte se passarmos a entender mais um plano das regras. ou seja, O "Terceiro Plano", no qual podemos entender que, numa atividade esportiva, os objetivos de ação se baseiam na verdade através de atividades inconsequentes. Afinal, é esta inconsequência que constitui a essência do Esporte, e podemos dizer que é o que esta por trás de um pensado não dito, ou, ainda, que ela é o não dito do pensado dito.

Vokamer (1987) alerta que este terceiro plano constitui o Sentido dos Sentidos do esporte e deixa o segundo plano mais compreensível, e sua efetividade é possível de entender pelo fato de que, neste mundo, não precisamos necessariamente reagir às estritas necessidades da vida, mas também temos a liberdade de realizar o Não- Necessário. Embora se deva considerar que esse plano das realizações Não-Necessárias é praticamente impossível de se encontrar atualmente no âmbito dos esportes, ele é a base, com certeza, de toda a atividade na música, por exemplo.

Já vimos anteriormente que o render e produzir para ganhar níveis cada vez maiores de rendimento é uma constante no ensino dos esportes. É preciso, portanto, encontrar algumas dimensões no próprio sentido do rendimento que oferecem outros valores ao render e produzir para o esporte. Por exemplo, se no ensino dos esportes o professor se interessar apenas pelo primeiro plano das regras acima expostas, ou seja, as regras oficias das modalidades esportivas, na forma de execução de ações que apenas contemplam o cumprimento das regras, este professor pode estar obrigando seus alunos a realizar ativida- 
des sem sentidos para eles. O produzir rendimentos no esporte sem sentido, isso pode ser considerado idêntico à domesticação.

A partir apenas deste plano, também não é possível que os alunos entendam certas concepções relacionadas aos esportes, mesmo que estes recebam conteúdos para serem intelectualmente compreensíveis, como, por exemplo, o entendimento objetivo das regras do primeiro plano. Para que os alunos entendam diferentes concepções do esporte, é necessário desenvolver o segundo e principalmente o terceiro plano das regras. O segundo plano permite ao aluno o desenvolvimento de uma autoexistência-com-sentido do esporte, afirma Volkamer (1987). E somente levando em consideração o terceiro plano pode-se alcançar uma compreensão sem cair numa "redução de complexidade" do mesmo nem domesticar pelo esporte ou realizar apenas adaptações funcionais no praticante. Só assim é possível educar pelo esporte.

Portanto, entender o esporte pelo rendimento apenas necessário e não obrigatório quer também significar que, na escola, como já afirmava Geoge Snyders (1988 e 1996 ), não se deve introduzir tipos de rendimento que não remetam ou introduzam a uma educação crítica e emancipatória, ou seja, ao desenvolvimento de capacidades de auto e co-determinação, além da crítica e do juízo de valores.

Isto significa também uma capacidade do distanciamento fundamentado em relação às exigências de rendimento do contexto sócio-cultural e esportivo, privilegiando assim também a criatividade do aluno. Por último, significa também que, tanto para a escola como para o esporte, deveria existir sempre a possibilidade de uma prática pedagógica para desenvolver capacidades nos alunos de superar as expectativas sociais de rendimentos baseados unicamente nos princípios das sociedades de rendimento atual que valorizam apenas o que um indivíduo produz ou o que ele é capaz de render. (Kunz, 2000)

O sentido humano do rendimento não é atingido quando o rendimento a ser atingido é determinado pelos resultados finais e suas consequências usando, como no caso do esporte, o critério "Alcançar Êxitos e Sucesso" com finalidades pré-determinadas estiver acima do "Caminho da Aprendizagem" para um aprender a aprender. Caso seja possível lançar o aluno no caminho da aprendizagem num aprender a aprender, não ocorre mais o processo de rendimento como nos princípios de rendimento do contexto social e econômico que conhecemos, ou seja, o rendimento deixa de ser obrigatório e passa a ser necessário pela compreensão de todos dessa imprescindível necessidade.

A fixação nos critérios do obter êxito e sucesso através de objetivos externamente colocados, infelizmente não a encontramos atualmente apenas no esporte de alto rendimento, mas nas modernas salas de musculação das academias, onde pessoas passam às vezes treinando até seis horas por dia sem serem atletas. Até mesmo os famosos corredores de rua que realizam essa prática para simplesmente se condicionar fisicamente podem estar atendendo apenas aos apelos socialmente estabelecidos do rendimento. Ou seja, quando 
não mais levam em consideração advertências do organismo como dores, tonturas, cansaço em excesso e etc. em função do cumprimento de objetivos préestabelecidos pela quantidade de voltas na pista, km percorridos ou tempo de corrida. Verifica-se, nestes casos, exatamente a mesma cega perseguição a atividades que levam ou levariam a êxitos e sucesso individual, ou seja, que atendem ao apelo social do rendimento obrigatório, perdendo assim a liberdade de render o necessário a partir de apelos internos, e não de exigências externas.

\section{CONCLUINDO}

Sabemos ser nada fácil numa sociedade de rendimento, na qual o esporte adquiriu nos últimos tempos um poder muito grande no imaginário social dos jovens, especialmente, transformar a concepção de um rendimento que é exigido e - portanto obrigatório - para um rendimento possível ou necessário. Acima de tudo, não é possível alcançar tal meta com meras práticas, diferenciadas que sejam. Há a necessidade de esclarecimentos. Estes esclarecimentos libertam o jovem das amarras de uma menoridade intelectual voluntária, como dizia Kant em Was ist Auflrärung (1974). Com um bom esclarecimento histórico, social e cultural sobre o esporte, além de seu conteúdo prático, é possível potencializar o aluno para esta libertação, ou seja, devem ser levados a ele esclarecimentos que não apenas se referem ao fenômeno esportivo simplesmente, mas a uma melhor compreensão de Mundo, de Sociedade, de Ser Humano, de si próprio e de toda complicada teia de relações com que convivem diariamente.

Por último, os abrangentes esclarecimentos acima mencionados ainda não são suficientes para mudar uma prática tão enraizada na cultura e no imaginário social de jovens em nossas escolas, como os esportes. É preciso mais. É preciso que os conteúdos práticos de um ensino dos esportes na escola avancem também para uma ideia de movimento humano que não se limita a um copiar e imitar gestos padronizados ou destrezas estereotipadas do esporte, mas que concebe uma ideia do "Se-Movimentar Humano" conforme apresentada no Brasil por Kunz $(1991,1994)$ e Trebels (1992 e 2006), especialmente. Essa ideia do "Se-Movimentar" possibilita que o ensino dos esportes não se concentre apenas nos movimentos técnicos de cada modalidade esportiva, e sim no sujeito com intenções de praticar esportes. Potencializa-se assim o sujeito a realizar os movimentos necessários para uma boa prática, uma prática prazerosa e não o obriga a copiar e repetir movimentos que se entendam obrigatórios para uma prática que se conceba "correta" independentemente do prazer que isso causa. Só assim é possível descobrir novamente que o aluno tem grande interesse e vontade de render nos esportes não quando for obrigatório, mas quando ele próprio concluir que existe uma necessidade de render para praticar esportes de forma bem-sucedida e com grande prazer. 


\section{REFERÊNCIAS}

KANT, E., et allii - Was ist Auflärung. Stuttgart, Reclam, 1974.

KUNZ, E. - Educação Física: Ensino \& Mudanças. ljuí, Unijuí, 1991

------- - Transformação didático-pedagógica do Esporte. ljuí, Unijuí, 1994.

------- - Esporte: uma abordagem com a fenomenologia. Revista

Movimento. № 12, ESEF/UFRGS, Porto Alegre, p. 19-27, 2000.

KUNZ, E. ; TREBELS, A. H. - Educação Física Crítico-Emancipatória - com uma perspectiva da pedagogia alemã de esportes. ljuí, Unijuí, 2006.

SNYDERS, G. - Alegria na Escola. São Paulo, Manole, 1988.

SNYDERS, G. - Alunos felizes. São Paulo, Paz e Terra, 1996.

TREBELS, A.H.- A concepção dialógica do movimento humano. Uma teoria do "se-movimentar". In: Kunz, E./Trebels, A.H. (org.) Educação Física CríticoEmancipatória: com uma perspectiva da pedagogia alemã do esporte. ljuí, Unijui, 2006.

TREBELS, A.H. - Plaidoyer para uma diálogo entre teorias do movimento humano e teorias do movimento no esporte. In: Revista Brasileira de Ciências do Esporte, ljuí, Unijuí, 1992.

TREBELS A,H, - Bewegungsunerricht und Sport - eine Beziehung auf Distanz. Manuskript, Hannover, 2009.

VOLKAMER, M. - Von der Last MIT der Lust im Schulsport. Frankfurt a.m. Schondorf, 


\section{ACCOMPLISHING AND PRODUCING IN SPORT: OBLIGATORY PERFORMANCE OR NE- CESSARY PERFORMANCE?}

\section{ABSTRACT}

The term "performance sport" is very well known among professionals in Physical Education and Sports. However, its meaning in general only refers to high performance or competition sports. In this article, we want to revisit the issue of high performance sports, especially for those who do not want or need high performance, as in the case of school sports. We present, therefore, a plädoyer for performance sports at school, where the students are free to perform what they can, and not obliged to accomplish what they cannot, that is to say, to be beyond their capabilities.

Keywords: Sport. Teaching. Students.

\section{EL CUMPLIMIENTO DE LA PRODUCCIÓN Y EN EL DEPORTE: EL RENDIMIENTO O LA EJECUCIÓN OBLIGATORIO ES NECESARIO?}

\section{RESUMEN}

El término "rendimiento deportivo" es muy conocido entre los profesionales de la Educación Física y Deportes. Sin embargo, su significado, en general, sólo se refiere a un alto rendimiento o deporte de competición. En este artículo, queremos retomar el tema de los deportes de alto rendimiento, especialmente para aquellos que no quieren o necesitan un alto rendimiento, como en el caso de deportes de la escuela. Se presenta, por tanto, un plädoyer para los deportes de rendimiento en la escuela, donde los estudiantes son libres para llevar a cabo lo que puede, y no está obligado a cumplir con lo que no pueden, es decir, ser más allá de sus capacidades.

Palabras clave: Deporte. Enseñanza. Estudiantes.

\section{Endereço para correspondência: andrizec@yahoo.com}

